\title{
O CRITICAL LEGAL STUDIES COMO FORMA DE EXPLICAR A INJUSTIÇA AMBIENTAL
}

Manuela Braga Fernandes ${ }^{i}$

Sumário: 1 Introdução. 20 movimento do Critical Legal Studies. 3 Os paradigmas da justiça ambiental e ferramentas para sua efetivação. $4 \mathrm{O}$ CLS como forma de abordar a garantia da justiça ambiental: o caso do condomínio Alamoana. 5 Conclusão. Referências.

\section{Resumo}

A justiça ambiental é um movimento de distribuição equitativa de ônus e bônus da exploração do meio ambiente. Da mesma forma, pode significar a atuação do Poder Judiciário no sentido de garantir efetividade do cumprimento da legislação ambiental. Assim, justiça ambiental pode ser a jurisprudência que se constrói no dia a dia para promover a proteção do meio ambiente. Por essa razão, a figura do magistrado tem um papel relevante na garantia da justiça ambiental, na medida em que é ele o efetivador da norma de proteção ao meio ambiente. O propósito do presente trabalho é tomar o referencial do Critical Legal Studies para compreender as decisões judi- 
ciais contrárias à proteção do meio ambiente. $\mathrm{O}$ CLS e seu conceito de ideologia dominante podem explicar o fenômeno das decisões opostas à manutenção do meio ambiente sadio. $\mathrm{O}$ teste para essa problemática vai ser a análise do caso do condomínio Alamoana, empreendimento imobiliário na cidade de João Pessoa.

Palavras-chave: Meio ambiente. Justiça ambiental. Critical Legal Studies. Efetividade do cumprimento da legislação ambiental.

\begin{abstract}
Environmental justice is a movement that claims for equal distribution on onuses and bonuses regarding the exploration of the environment. It may also mean the Judiciary system's performance on the fulfilling of the environmental legislation. So, environmental justice may be the jurisprudence constructed on a daily basis that promotes environmental protection. For that reason, the judge has a relevant position on the assurance of environmental justice because he has the power to concretize the protective legislation. The purpose of this work is to take the Critical Legal Studies theory to understand judicial decisions that go against the protection of the environment. CLS and its concept of dominant ideology may explain the phenomenon of decisions that go against the maintenance of a healthy environment. The test to this problem will be the analysis of the case of the Condomínio Alamoana, a real state enterprise located at João Pessoa.
\end{abstract}

Keywords: Environment. Environmental justice. Critical Legal Studies. Effectiveness of environmental compliance.

\section{INTRODUÇÃO}

A temática da justiça ambiental lato sensu não vai tratar apenas da questão da escassez ou da preservação do meio ambiente, mas também da distribuição de recursos e dos ônus ambientais. A comunidade negra americana começou a perceber uma política pública ambiental que desfavorecia as suas localidades, sofrendo especialmente com despejo de dejetos nos seus arredores. Nasceu, então, a chamada justiça ambiental, um conjunto de princípios que clamam pelos direitos ambientais sem qualquer distinção de cor. A partir daí o movimento globalizou-se e passou a agregar não só comunidades negras, mas todos os cidadãos que lutam pela devida garantia de direitos ambientais.

Uma vez estabelecida a temática da justiça ambiental como um movimento internacional de distributividade de encargos negativos de recursos ambientais, faz-se mister dizer que o termo também vai significar a atuação do Poder Judiciário nacional no sentido de melhor garantir a efetividade dos direitos ambientais da sociedade. Assim, na mesma medida, a justiça ambiental é também a jurisprudência que se forma no dia a dia do Judiciário de modo a promover a efetivação das previsões legais acerca de proteção ambiental e dos princípios gerais do tema.

Nesses termos, o Poder Judiciário, na figura do juiz, deve ser o maior garantidor de justiça ambiental, já que assume o papel de efetivador da lei. É necessário que faça os contornos para que seja justo no caso concreto, pois a legislação é letra morta e não é capaz de acompanhar as peculiaridades que o dia a dia propõe para o magistrado. Assim, usando de sua própria consciência, permitindo sua personalidade aflorar na sentença, é possível garantir justiça ambiental.

O fato é que a decisão judicial é uma decisão pessoal fundamentada, a posteriori, em direito. Assim, agarantiadajustiçaambientalvaiacontecer à medida que o juiz responsável pela causa esteja disposto a assim fazer. No entanto, muitas vezes o magistrado assume uma postura que não entra 
em acordo com esses preceitos de pró-atividade na feitura de justiça ambiental. A ideia, então, é usar os ensinamentos do Critical Legal Studies (CLS) como marco teórico para desvendar os interesses por trás dessas decisões contrárias à garantia de justiça ambiental. O CLS concebe o direito como instrumento de dominação de classe, sempre servindo a determinados nichos sociais e entendendo a permeabilidade que se dá entre direito e política.

A hipótese para essa problemática é que os ensinamentos do CLS acerca de encontrar a ideologia dominante que se esconde na decisão judicial vão explicar as decisões judiciais que se esquivam de garantir justiça ambiental. $\mathrm{O}$ teste para essa hipótese vai ser verificado no caso do condomínio Alamoana, um empreendimento residencial na cidade de João Pessoa que está em área de preservação e que não cumpriu os requisitos legais para lá se estabelecer.

Portanto, num primeiro momento, o presente trabalho vai desvendar o movimento do CLS para, em seguida definir os parâmetros da justiça ambiental. Por fim, vai trazer os questionamentos do CLS para a justiça ambiental através do paradigma exemplificativo do condomínio Alamoana.

\section{O MOVIMENTO DO CRITICAL LEGAL STUDIES}

O Critical Legal Studies, ou CLS, é considerado por seus próprios pensadores um movimento, um jeito de pensar o direito que rejeita o apego ao positivismo e clama por um olhar crítico no estudo do direito. É um movimento intelectual americano que tenta entender os fenômenos jurídicos a partir dos ensinamentos pragmáticos e realistas, sem se desprender dos parâmetros marxistas e feministas. ${ }^{1}$

O movimento nasceu a partir de um encontro de professores de direito na Universidade de Wisconsin em 1976. Nesse encontro foi formado um grupo de discussões que mais tarde se espalhou, ganhando adeptos nas universidades de Harvard e Yale. Entre seus maiores expoentes, hoje, estão Roberto Mangabeira Unger, Duncan Kennedy, Mark Tushnet, Morton Horwitz e Elisabeth Mensch.

O CLS dedica boa parte de suas energias a uma profunda e engendrada crítica ao liberalismo, correntetãoadstritaaomododepensaramericano, proclamando a indeterminação do direito que emergiu no ambiente do modo de produção capitalista. A maioria de seus pensadores são herdeiros do ativismo político dos anos 60 e 70 nos Estados Unidos e se concentraram em pensar o direito como ideologia, como legitimação e como força hegemônica ${ }^{2}$.

Duncan Kennedy demonstra a ambivalência no CLS ao esclarecer que, se de um lado o movimento insiste no direito como campo autônomo de luta cultural e política, de outro, empenha-se em demonstrar as incoerências e as contradições do direito ${ }^{3}$. Assim, ao mesmo tempo que o direito é elemento de mudança, é também mecanismo defeituoso, que precisa sofrer uma renovação para servir a seus fins.

Um dos principais pleitos do CLS nos seus primeiros dias era o fim da exclusão das questões de justiça social, econômica e sexual dos programas de ensino do direito, o que, alegavam, favorecia a manutenção do statu quo. O direito seria, nesses termos, um instrumento de manutenção da ordem vigente, que se contrapõe à ideia do movimento, que coloca o direito como fator de mudança.

Para Duncan Kennedy, o CLS parece ter falhado como instrumento de transformação da sociedade, mas obteve sucesso na mudança dessa educação jurídica lacunosa. O CLS desafiou o ensino clássico do direito, instituindo a hermenêutica e questões mais desafiadoras referentes a sociedade, justiça e sexo como parte do programa de educação no direito. No entanto, para ele, o ambiente do curso de direito ainda reproduz convenções de poder: os professores são

GODOY, Arnaldo. O critical legal studies movement de Roberto Mangabeira Unger. Revista Jurídica. Brasília, v. 8, n. 82, p. 49-63, dez./jan. 2007 ${ }^{2}$ ARNAUD, André-Jean et al. (Org.). Dicionário enciclopédico de teoria e sociologia do direito. Trad. Patrice Charles e F. X. Willaume. Rio de Janeiro: Renovar, 1999.

${ }^{3}$ ARNAUD, André-Jean et al. (Org.). Dicionário enciclopédico de teoria e sociologia do direito. 
majoritariamente brancos, do sexo masculino, pretensamente corretos nas suas atitudes e com todas as características da classe média. ${ }^{4}$

Os Estados Unidos, berço dos crits, nunca foram um país que favoreceu o crescimento da esquerda. Traz consigo um viés liberal e conservador adstrito à cultura e modo de pensar majoritários. O CLS, então, tem um papel importante na formação de uma esquerda jurídica, de modo que pode promover debates mais institucionalizados acerca do ensino do direito.

Dessa forma, sob o jargão "direito é política", o CLS apresenta para o direito uma abordagem pós-positivista, esquerdista e hermenêutica. Critica a ideia de que o conhecimento científico é sempre neutro e objetivo, o que condiz com o pragmatismo de William James, em que verdades são posições pessoais e a ciência se faz com subjetividade. $^{5}$

De fato, o CLS tem a mesma origem que o realismo jurídico americano, ambos herdeiros do pragmatismo filosófico do final do séc. XIX. Mangabeira Unger entende que qualquer doutrina jurídica deve representar o que se propõe a explicar em termos de vida real, deve trazer consequências práticas ${ }^{6}$, revelando a influência do pragmatismo filosófico, conjunto teórico que desdenha de qualquer filosofia que não proponha resultados práticos. Não há como dissociar o pensamento jurídico de suas próprias razões, sua maneira de entender o entorno. É preciso negar a metafisica, como fez o pragmatismo anteriormente, e negar a filosofia do direito que rejeita o estudo das consequências práticas desse direito.

O realismo jurídico foi o primeiro herdeiro do pragmatismo, mas se pode dizer que o CLS deu continuidade ao realismo, promovendo a subjetividade encontrada através do empirismo acima do apego irrestrito à lei. No entanto, o CLS critica frequentemente o realismo na medida em que entende que este adotou apenas um ceticismo moderado, ainda crente e permissivo diante do positivismo jurídico.

Um dos principais realistas é Benjamin Cardozo, juiz da Suprema Corte americana entre 1932 e 1937. Ele entendia que cada indivíduo não apenas tem suas próprias crenças, sua filosofia de vida, mas é impossível separar essa filosofia do seu trabalho de magistrado. Descrevendo a sutileza das forças subconscientes que regulam a infusão de nossas decisões, Cardozo recorda James quando diz que:

\begin{abstract}
Cada um tem uma filosofia básica de vida, mesmo aqueles para os quais os nomes e as noções de filosofia são desconhecidos ou constituem anátema. Há em cada um de nós uma torrente de tendências, quer se queira chamá-la filosofia ou não, que dá coerência e direção ao pensamento e à ação. Os juízes não podem escapar a essa corrente.
\end{abstract}

No entanto, Cardozo, apesar de entender que o magistrado tem o condão de influenciar a concretização do direito, na medida em que atribui sentido à norma e este sentido passa pelo filtro da personalidade e crenças pessoais, não defende o decisionismo irrestrito. Ele desenvolve métodos que explicam o processo de decisão que o magistrado faz uso, mas os condiciona em todos os termos a adesão ao precedente. Assim, quando constrói os métodos da filosofia, tradição, história e sociologia, está, na verdade, admitindo que, apesar da decisão judicial ser um processo pessoal, é algo organizado do ponto de vista normativo, na medida em que o magistrado deve estar apegado ao precedente ${ }^{8}$. Como Lorena Freitas $^{9}$ ensina, o realismo jurídico, ao dizer que direito é o que os juízes dizem que é direito, assim o faz sem se desprender da norma ou da adesão ao precedente.

Desse modo, é possível notar a postura moderada do realismo, que se coloca entre o

\footnotetext{
${ }^{4}$ GODOY, Arnaldo. O movimento Critical Legal Studies e Duncan Kennedy: notas sobre a rebeldia acadêmica no direito norte-americano. Disponível em: <http://www.arnaldogodoy.adv.br/artigos/kennedy.htm>. Acesso em: 16 ago. 2013.

${ }^{5}$ JAMES, William. Pragmatism's conceptions of truth. New York: Dover Publications, 1986.

${ }^{6}$ GODOY, Arnaldo. O critical legal studies movement de Roberto Mangabeira Unger. Revista Jurídica. Brasília, v. 8, n. 82, p. 49-63, dez./jan. 2007.

${ }^{7}$ CARDOZO, Benjamin. The nature of judicial process. New York: Dover, 2005.

${ }^{8}$ CARDOZO, Benjamin. The nature of judicial process.

${ }^{9}$ FREITAS, Lorena de Melo. O realismo jurídico como pragmatismo: a retórica da tese realista de que direito é o que os juízes dizem que é direito. Recife: o autor, 2009.
} 
formalismo positivista e o puro decisionismo. O CLS deu continuidade ao realismo de modo critico, com viés de esquerda, usando um ceticismo mais radical.

O que Cardozo chamou de elementos subconscientes podem ser trazidos para o CLS como ideologia ${ }^{10}$.

Para Kennedy ${ }^{11}$, duas ideologias vão moldar o pensamento e a produção do direito nos EUA: liberalismoeconservadorismo.Éprecisoobservar aqui que o âmbito de produção do direito que se fala não é o legislativo, mas o judiciário, pois para o CLS o direito é criado pelo Poder Judiciário. Então quando o CLS fala que o liberalismo e o conservadorismo regem a formatação do direito está dizendo nada mais que assim o fazem na medida em que essas ideologias permeiam a atuação dos juízes, responsáveis pela decisão judicial e, por isso, pela produção do direito.

Ideologia é a pretensão de universalizar a forma de pensar as relações sociais que está intrinsecamente relacionada com a defesa de interesses de grupos. A defesa dessa ideologia, para o CLS, se dá através do comportamento estratégico: a atitude do juiz de decidir de acordo com suas preferências externas ao direito, que se relacionam muito mais com questões de ordem social e politica, para depois fundamentar essa decisão externa num material jurídico.

Com isso, Kennedy ${ }^{12}$ ensina que é necessário assumir uma hermenêutica de suspeita, isto é, uma postura de desconfiança sempre tentando relacionar o discurso jurídico com um discurso político. Ou seja, é preciso não acreditar nas características normalmente atribuídas ao direito, como neutralidade, objetividade ou racionalidade. Hermenêutica de suspeita é a postura cética diante do positivismo jurídico, o entendimento de que a produção jurídica dos tribunais estaria diretamente relacionada a um discurso político, o que explica a máxima de que "direito é política".

A retórica jurídica, mascarada através de toda sua técnica positivista de aplicação, esconderia que o direito é, na verdade, um mecanismo de institucionalização de interesses de grupos sociais. ${ }^{13} \mathrm{~A}$ decisão judicial seria, então, orientada pela preferência ideológica do julgador.

O julgador tem uma variedade de materiais jurídicos dos quais, ao menos um, deve servir para justificar sua decisão pessoal, advindo de sua ideologia. Essa ideologia pode ser particular ou pode ser uma ideologia de classe, intrinsecamente relacionada ao statu quo social e econômico.

Os interesses de grupo - isto é, a ideologia são assimilados pelo corpo político sob a forma de leis, transformando a ideologia em direito e permitindo que o grupo dominante formule demandas baseado em fundamentos jurídicos, não mais meras preferências ${ }^{14}$.

No direito ocidental, o discurso de qualquer autoridade, entre elas o magistrado, tenta legitimar o poder do Estado. A maneira tradicional positivista de entender o direito nega dois aspectos importantes acerca da legitimação do poder do Estado. O primeiro deles seria o fato de que o direto dá a um cidadão um grau de poder em detrimento de outros cidadãos, ou até mesmo promove graus diferentes de poder entre determinados grupos e, assim, a classe dos magistrados é um desses grupos privilegiados. A institucionalização dessas hierarquias promove a reprodução cristalizada desse poder dentro da sociedade. A cultura e o próprio costume da sociedade ensina que o juiz é alguém superior, ele está numa hierarquia acima dos demais essa é a mensagem transmitida pelo Estado para

\footnotetext{
${ }^{10}$ MEDEIROS, Gilmara Joane Macedo. Realismo Jurídico e Critical Legal Studies: diferentes posturas críticas do direito. Anais... II Encontro PROCAD UFAL-UFPE-UFPB. Recife, 2011.

${ }^{11}$ KENNEDY, Duncan. La critica de los derechos em los Critical Legal Sudies. Disponível em: <http://www.palermo.edu/derecho/publicaciones/pdfs/ revista_juridica/n7N1-Julio2006/071Juridica02.pdf>. Acesso em: 19 ago. 2013.

${ }^{12}$ KENNEDY, Duncan. La critica de los derechos em los Critical Legal Sudies. Disponível em: <http://www.palermo.edu/derecho/publicaciones/pdfs/ revista_juridica/n7N1-Julio2006/071Juridica02.pdf>. Acesso em: 19 ago. 2013.

${ }^{13}$ KENNEDY, Duncan. La critica de los derechos em los Critical Legal Sudies. Disponível em: <http://www.palermo.edu/derecho/publicaciones/pdfs/ revista_juridica/n7N1-Julio2006/071Juridica02.pdf>. Acesso em: 19 ago. 2013.

KENNEDY, Duncan. La critica de los derechos em $l$

${ }^{14}$ KENNEDY, Duncan. La critica de los derechos em los Critical Legal Sudies. Disponível em: <http://www.palermo.edu/derecho/publicaciones/pdfs/ revista_juridica/n7N1-Julio2006/071Juridica02.pdf>. Acesso em: 19 ago. 2013.
} 
a sociedade. ${ }^{15}$

Da mesma forma, no segundo ponto, o positivismo entende que o sistema tem lacunas, conflitos e ambiguidades e que estas devem ser resolvidas pelos juízes. Esses magistrados têm consciência ou semiconsciência da ideologização do estado positivista, que promove uma formatação hierárquica da ordem social ${ }^{16}$, colocando eles mesmos, os juízes, numa posição superior. Essa observação aponta a parcialidade do magistrado no momento da decisão, na medida em que tem o Estado a seu favor e como seu legitimador, engrandecendo-o hierarquicamente.

Kennedy ${ }^{17}$ aponta a ingenuidade de se acreditar que o magistrado apenas aplica a lei, mas não cria norma ele mesmo. A ideologia permeia o discurso normativo na medida em que os magistrados usam o comportamento estratégico anteriormente mencionado para decidir. Assim o fazem sabendo que podem contar com a hierarquização a seu favor como forma de proteção, bem como têm interesse na sua manutenção.

Numa situação hipotética de transparência quanto à permeabilidade de ideologias pessoais no discurso jurídico, o resultado político seria diferente do que se tem em regra, a retórica da subsunção do fato à norma. Tal hipótese promoveria a consciência geral de que a política faz parte da decisão judicial. O CLS tenta promover justamente o fim dessa ilusão, de modo que seja possível para todos conceber que um juiz pode estar agindo de forma parcial, ou mesmo de má-fé, se essa decisão for a favor ou contra sua ideologia. Para os crits, tem que se quebrar o paradigma do juiz protetor, é preciso desconfiar da suposta neutralidade que permeia os limites da decisão judicial.

Os crits defendem o fim da concepção da lei sob o viés da objetividade. A própria criação legislativa segue parâmetros de julgamentos de valor, opções e alternativas, especialmente nas normasabertas, que são conceitoseminentemente subjetivos. Usar a lei como instrumento objetivo e, por isso, facilmente controlável é um erro. A lei não tem o condão de controlar a decisão do magistrado.

O objetivismo é a crença que leis e precedentes detêm autoridade plena sobre o instrumental jurídico. Mas Mangabeira Unger ensina que o objetivismo é apenas um mecanismo que afasta o entorno, as ideologias políticas e sociais do seu vínculo com a realidade jurídica. ${ }^{18}$

O objetivismo tenta dotar de realidade o kelsianismo puro, centrado em problemas formais. $O$ jurista moderno tenta tratar os problemas jurídicos sem tocar no assunto de interesses de grupos ou em política, invocando a impessoalidade na aplicação do direito. $O$ que o CLS defende é que isso é impossível, a subjetividade resiste no direito no momento que a decisão judicial passa pelo crivo subjetivo da ideologia do magistrado.

Reforça-se, então, a hermenêutica da suspeita. Qualquer cidadão que se preste a interpretar o direito deve ter em mente a busca da motivação ideológica embutida na decisão. A decisão de direito é ensinada a se revestir de caráter de objetividade, impessoalidade ou neutralidade, mas é possível encontrar por trás dessa decisão as verdadeiras motivações do juiz. Para os CLS, o magistrado aproxima a justificação legal do discurso político vigente, aquele que o convence em razão de ser o discurso de dominação política. Essa dominação vem justamente trazer a conotação de hierarquia da qual o juiz, como aponta Kennedy, beneficia-se.

O fato de que cada decisão é revestida de uma posição ideológica é inferência lógica da admissão de que qualquer decisão judicial é uma decisão pessoal, decisão do magistrado que a profere, e, por isso, traduz as idiossincrasias de cada um.

\footnotetext{
${ }^{15}$ KENNEDY, Duncan. La critica de los derechos em los Critical Legal Sudies. Disponível em: <http://www.palermo.edu/derecho/publicaciones/pdfs/ revista_juridica/n7N1-Julio2006/071Juridica02.pdf>. Acesso em: 19 ago. 2013.

${ }^{16}$ GODOY, Arnaldo. O movimento Critical Legal Studies e Duncan Kennedy: notas sobre a rebeldia acadêmica no direito norte-americano. Disponível em: <http://www.arnaldogodoy.adv.br/artigos/kennedy.htm>. Acesso em: 16 ago. 2013.

${ }^{17}$ O movimento Critical Legal Studies e Duncan Kennedy: notas sobre a rebeldia acadêmica no direito norte-americano. Disponível em: $<$ http://www. arnaldogodoy.adv.br/artigos/kennedy.htm>. Acesso em: 16 ago. 2013.

${ }^{18}$ GODOY, Arnaldo. O critical legal studies movement de Roberto Mangabeira Unger. Revista Jurídica. Brasília, v. 8, n. 82, p. 49-63, dez./jan. 2007.
} 
Kennedy ${ }^{19}$ traz, então, a proposta de um pós-direito, que é a aceitação de que a crença no poder judiciário vem da fé que se tem nos direitos subjetivos. O Estado democrático, com suas heranças jusnaturalistas, leva os cidadãos a acreditarem em direitos primígenos, direitos que fundamentam todos os direitos, o direito de se ter direitos, a garantia jurídica de se ter justiça. Com a ruptura dessa fé, é possível enxergar a produção do direito como realmente é, uma afirmação de ideologias dominantes.

Kennedy é um dos principais críticos da postura mítica dos magistrados como figura popular que detém verdades e poderes maiores que os demais. Esse ideário serve apenas para construir a ideia de que os magistrados estariam acima de interesses pessoais, disposições partidárias ou compromissos ideológicos. A cultura do direito parece colocar o juiz como ícone despersonalizado de uma intuição moral incorruptível, como se seu trabalho trouxesse como resultado nada além da verdade. O juiz não é o defensor do cidadão comum, ele foi colocado numa situação hierárquica de poder e tem o condão de decidir sobre os demais de acordo com suas próprias convicções, o que não faz dele, de nenhuma forma, um protetor incorruptível do seu menor hierárquico.

A reinvindicação da Critical Legal Studies é de que absolutamente não há como falar de forma politicamente neutra e coerente quando se refere a uma decisão judicial. Se o realismo jurídico entende que o resultado de um processo judicial pode ser diferente do que está na lei, o CLS defende que a classe dominante vai garantir que esse resultado não esteja contrário aos seus interesses. $O$ garantir que esse resultado não esteja contrário aos seus interesses. $O$ movimento substituiu as principais ideias do pensamento jurídico moderno pela análise da concepção da lei, uma abordagem política no estudo do direito ${ }^{20}$.

Assim, o CLS é um movimento que estuda o direito desconfiando da neutralidade e da objetividade na decisão judicial. Essa postura crítica de abordagem do direito permite trazer explicações na análise casuística de diversas matérias de direito que parecem desafiar o homem comum que tenta analisar a decisão sob o viés meramente legal. O CLS vai trazer um olhar fresco para a realidade jurídica que se tem no dia a dia da operação do direito, de forma a explicar fenômenos que o positivismo esquivouse de responder.

A questão da garantia da justiça ambiental pode ser um desses fenômenos quando se analisa casos em que o Judiciário é faltoso em cumprir os requisitos legais de maior obviedade. Muitas vezes os magistrados parecem sair do seu lugar comum para justificar uma decisão que traz respaldos negativos sobre o meio ambiente. A análise de decisões desse tipo sob o olhar crítico do CLS pode promover explicações suficientes para a situação.

\section{OS PARADIGMAS DA JUSTIÇA AMBIENTAL E FERRAMENTAS PARA SUA EFETIVAÇÃO}

A temática da justiça ambiental lato sensu não vai tratar apenas da questão da escassez ou da preservação do meio ambiente, mas também da distribuição de recursos e dos ônus ambientais.

Assim, justiça ambiental é mais que falar em jurisprudência ambiental, é, em verdade, um movimento social que nasceu nos EUA dos anos 80. A comunidade negra americana começou a perceber uma política pública ambiental que desfavorecia as suas comunidades, sofrendo com despejo de dejetos ou mesmo o esquecimento completo das suas próprias necessidades. Nasceu, então, a chamada justiça ambiental, um conjunto de princípios que clamam pelos direitos ambientais sem qualquer distinção de cor. A partir daí o movimento globalizou-se e passou a agregar não só comunidades negras, mas todos os cidadãos que lutam pela devida garantia de direitos ambientais e se sentem inferiorizados, arcando com os prejuízos de políticas públicas

${ }^{19}$ KENNEDY, Duncan. A critique to adjdudication. Cambridge: Harvard University Press, 1997.

${ }^{20}$ UNGER, Roberto M. The Critical Legal Studies movement. Cambridge: Harvard University Press, 1983. 
prejudiciais. $^{21}$

Dessa forma, o conceito de justiça ambiental está mais relacionado à justiça distributiva, tem como principal fundamento a distribuição equitativa dos danos ambientais. O enfoque aqui é que todos arquem com os danos, não se fala nem em riquezas ou bônus, mas em ônus.

O movimento não só critica o crescimento econômico desenfreado, que não se preocupa com as questões ambientais, mas quer promover também uma ampliação nas discussões dentro da matéria ambiental. Promove um discurso de divisão das problemáticas ambientais, pois não existe um meio ambiente homogêneo, ele tem diferentes vieses que devem ser discutidos de maneiras diferentes. O que quer dizer é que a questão da água é diferente da questão de energia e esta, por vez, é diferente da de resíduos etc. Todas essas temáticas têm suas peculiaridades que devem ser tratadas separadamente, mas juntas formam as questões de direito ambiental. E é fazendo essa devida separação que se vai atingir a verdadeira justiça ambiental

O oposto da justiça ambiental é a injustiça ambiental, ou racismo ambiental, que se configura na distribuição desigual dos benefícios e dos impactos negativos das políticas ambientais entre os diferentes grupos da sociedade. Quando há uma situação em que um determinado grupo social não tem acesso aos recursos e ao mesmo tempo arca com todos os custos dos impactos ambientais negativos, tem-se consolidada a injustiça ambiental.

As discussões acerca da justiça ambiental começam a acontecer no Brasil no ano 2000 com publicações e pesquisas na área. Em 2001, criou-se a Rede Brasileira de Justiça Ambiental (RBJA), que assumiu o compromisso de garantir que nenhum grupo social ou étnico suporte uma parcela desproporcional das consequências ambientais negativas, o acesso justo de todos aos recursos, acesso às informações relevantes sobre o tema e favorecimento à criação de novos grupos de proteção ${ }^{22}$.

A Rede tem investido em pesquisas que tentam relacionar a degradação ambiental com a desigualdade social e conclui que a exposição desigual da população a danos ambientais não decorre de uma condição natural geográfica, mas de processos sociais e políticos que promovem uma proteção desigual da população.

Um caso paradigmático de injustiça ambiental se deu em 1991 quando o chefe do Banco Mundial, na época, Lawrence Summers, propôs em um memorando, que vazou na mídia internacional, $o$ despacho dos impactos ambientais negativos para países mais pobres. Propunha, no documento, encorajar a migração da indústria poluidora para países subdesenvolvidos da África de modo a resolver o problema dos resíduos tóxicos, livrando-se deles no terceiro mundo. Ele segue dizendo que os países subpovoados da África são "subpoluídos"; afirma que ter boa qualidade do ar nesses lugares é ineficiente, sendo a melhor qualidade do ar mais proveitosa em cidades como Los Angeles ou Cidade do México. ${ }^{23}$

Não é só a África que sofre com a condição de ser área de descarte de rejeitos de países mais ricos, o Brasil tem registrados diversos casos de recepção de contêineres de lixo hospitalar e urbano dos EUA e da Inglaterra, como o emblemático caso das 46 toneladas de lixo hospitalar recebidos em Suape em 2011. É o que se chama de colonialismo tóxico.

A justiça ambiental vem então para combater essas práticas garantindo equidade e igualdade. $\mathrm{O}$ conceito social deve estar implícito na expressão justiça ambiental, pois não há verdadeira justiça sem que haja as garantias sociais dos cidadãos.

No entanto, uma corrente neomalthusiana tenta, nos dias de hoje, negar a injustiça ambiental. Seateoriamalthusianadefendiaqueocrescimento populacional acelerado era o causador de fome e miséria, a teoria neomalthusiana defende que a

\footnotetext{
${ }^{21}$ CASTILHO, Adriana Guedes de. Entre a justiça e a injustiça ambiental: atuação do poder judiciário nos conflitos ambientais. 2012, 114f. Dissertação (Mestrado)-Programa de Pós-Graduação em Ciências Jurídicas da Universidade Federal da Paraíba. João Pessoa, 2012.

${ }^{22}$ PACHECO, Tânia [Blog]. Combate racismo ambiental. Globo ecologia: entenda a importância do trabalho da rede brasileira de justiça ambiental. 10.07.2012. Disponível em: <http://racismoambiental.net.br/tag/rede-brasileira-de-justica-ambiental/>. Acesso em: 16 ago. 2013.

${ }^{23}$ CASTILHO, Adriana Guedes de. Entre a justiça e a injustiça ambiental: atuação do poder judiciário nos conflitos ambientais. 2012 , $114 \mathrm{f}$. Dissertação (Mestrado)-Programa de Pós-Graduação em Ciências Jurídicas da Universidade Federal da Paraiba. João Pessoa, 2012.
} 
crise ambiental se dá em razão de o crescimento populacional não acompanhar os recursos naturais finitos do planeta, que não consegue se regenerar a tempo. Essa ideia é facilmente refutável com um dado do programa das Nações Unidas para o Desenvolvimento, que revela que $20 \%$ da população consome $70 \%$ dos recursos do mundo. Assim, é a população mais abastada a responsável pela escassez dos recursos naturais.

Têm-se, ainda nesse campo, os ultraliberais, que acreditam que a melhor forma de combater a superexploração dos recursos naturais é privatizando-os. Dessa forma, os interesses econômicos das empresas promoveriam a preservação do meio ambiente. Para eles a falta de definição de propriedade privada sobre os recursos é que causa a degradação. No entanto, não discutem o fato de que ao colocar um dono nos recursos que são de todos estão negando o acesso da sociedade a eles.

Nesses termos, uma vez estabelecida a temática da justiça ambiental como um movimento internacional de distributividade de encargos negativos de recursos ambientais, faz-se mister dizer que o termo também vai significar a atuação do Poder Judiciário nacional no sentido de melhor garantir a efetividade dos direitos ambientais da sociedade. Assim, na mesma medida, a justiça ambiental é também a jurisprudência que se forma no dia a dia do Judiciário de modo a promover a efetivação das previsões legais acerca de proteção ambiental e dos princípios gerais do tema.

No seu comportamento, o Judiciário deve levar em consideração as responsabilizações penal, civil e administrativa que decorrem do dano ambiental. A responsabilidade civil deve ser objetiva, isto é, pouco importa se houve culpa ou dolo no evento danoso, havendo nexo de causalidade entre conduta do sujeito e dano está configurada a responsabilidade.

Sobre a responsabilidade penal, esta precisa de dois pressupostos para se configurar. Primeiramente, é preciso que a infração ambiental tenha sido resultante de uma decisão do representante da empresa; em seguida, é necessário que a decisão traga benefícios para essa companhia, que traga vantagens.
Os crimes ambientais estão regulamentados na Lei n. 9.605/1998, tendo sido revogados os crimes previstos no Código Penal e na legislação esparsa, sem prejuízo da aplicação subsidiária dos dispositivos do Código de Processo Penal e do Código Penal.

A responsabilização administrativa também é prevista da Lei n. 9.605/1998, art. 70, que considera infração administrativa ambiental toda ação ou omissão que viole as regras de proteção e recuperação do meio ambiente.

Como regra geral na proteção ambiental, o ordenamento jurídico promove alguns princípios ambientais que dão a ideia central do sistema. $\mathrm{O}$ princípio do ambiente ecologicamente equilibrado é um importante fundamento de proteção reconhecido internacionalmenteatravés da Declaração de Estocolmo. Há o princípio do poluidor-pagador, que aplica medidas coercitivas e sanções financeiras para o ente poluidor. Da mesma forma, os princípios da prevenção e precaução, que orientam no sentido de evitar o dano ambiental antes que aconteça, seja ele já definido (prevenção) ou não exatamente diagnosticado (precaução). O princípio da informação vai garantir a participação do cidadão no processo decisório em medidas ambientais. O princípio da reparação vem para garantir a obrigação de reparar daquele que causou dano, mitigando os impactos causados. O princípio do acesso equitativo tem importante papel na justiça ambiental, ao assegurar que todos tenham acesso aos recursos ambientais sem quaisquer distinções. O princípio do respeito à identidade vem para garantir o respeito a memória social e antropológica do meio cultural que se forma dentro do meio ambiental. E, por fim, o desenvolvimento sustentável, que busca um equilíbrio entre crescimento econômico, social e ambiental.

Comungando com esses princípios gerais, a legislação nacional prevê quatro atores sociais que vão exercer no Poder Judiciário a função de tutela da proteção ambiental. ${ }^{24}$ Esses sujeitos vêm para garantir a justiça ambiental como movimento social, mas também no sentido de promover decisões do dia a dia que respeitem o meio ambiente e promovam a longevidade dos 
recursos naturais. Esses atores são o Ministério Público, a Polícia, o Terceiro Setor e o próprio Poder Judiciário, na figura do magistrado, o que promove um importante elemento de conexão com o CLS, a ser abordado mais adiante.

A defesa do meio ambiente é tarefa, em primeira mão, do parquet. Essa mudança veio com a Lei n. 6938/1981, que atribuiu ao Ministério Público a faculdade de propor ações judiciais de natureza civil com o objetivo de reparar ou evitar danos ao meio ambiente. Essa lei também instituiu a responsabilidade objetiva do poluidor nos termos atuais, independente de culpa. Mas foi a Lei n. 7.347/1985 que efetivou a possibilidade de intervenção do Ministério Público Federal ou Estadual na tutela ambiental, instituindo a Ação Civil Pública.

Os anos 1980 trouxeram essas duas leis que colocam o Ministério Público no centro da proteção ambiental; também foram criados órgãos de proteção ao meio ambiente dentro da instituição, de modo a promover a garantia desses direitos difusos.

Mas é a Ação Civil Pública o principal mecanismo de proteção ambiental, podendo-se ainda mencionar a importância do Mandado de Segurança e da Ação Popular. Têm competência para propor a ACP, além do Ministério Público, a Defensoria Pública, União, estados, Distrito Federal, municípios, autarquias, empresas públicas ou sociedade de economia mista e associações. A ação deve ser proposta no foro em que ocorreu o fato danoso e pode ter como objeto a condenação pecuniária ou o cumprimento de obrigação de fazer ou não fazer. A coisa julgada vai ter efeito erga omnes.

A Lei n. 7.347/85, junto com a Ação Civil Pública, criou o Fundo de Defesa de Direitos Difusos, cujos recursos, advindos das sentenças condenatórias ou de multa, devem ser revertidos para a reparação dos danos.

É possível que as partes cheguem a um comum acordo, chama-se transação, que deve ser homologado judicialmente e impõe o compromisso de reparação do dano.

Existe ainda a possibilidade do compromisso de ajustamento de conduta, que não é um instrumento processual, em que o sujeito que causa dano ambiental se compromete a ajustar suas atividades aos padrões das normas ambientais. Uma vez celebrado, ele assume a natureza de título executivo extrajudicial, em caso de descumprimento. Os mesmos legitimados para ACP podem executar esse título extrajudicial.

O poder de polícia também é uma ferramenta de proteção ambiental. A polícia administrativa, que está presente na fiscalização dos órgãos administrativos (autos de infração), e a polícia judiciaria, que são as polícias civil e militar (inquéritos policiais), vão atuar na defesa do ambiente.

O Terceiro Setor, as entidades sem fins lucrativos, têm um papel complementar ao do Estado na garantia do meio ambiente equilibrado. Podem fazer essas garantias através de Ação Civil Pública, Mandado de Segurança coletivo e Ação Popular. Há a possibilidade também de intervirem em âmbito administrativo, interpondo recursos em processos licitatórios e participando de órgãos de controle ambiental como CONAMA ou SISNAMA. Ajudam ainda na pesquisa e educação em matéria ambiental, sendo estas uma das principais atividades das ONGs, seu trabalho de conscientização.

Por fim, o Poder Judiciário deve ser o maior garantidor de justiça ambiental já que a previsão legal é de que nenhuma ameaça ou lesão a direito pode ser subtraída de sua apreciação; e as ameaças ambientais se incluem aqui. A Ação Civil Publica é a maior ferramenta no sistema processual para efetivar os direitos ambientais; é o instrumento que vai acionar o Judiciário e incitar o momento da garantia efetiva de um direito que vem sendo desrespeitado. É o Judiciário, representado pelo magistrado, que vai efetivar o disposto em lei ou normas gerais. Ele vai também garantir a proteção coletiva em casos de danos muito fragmentados (como o consumo de produto estragado). É relevante o papel social do Judiciário na apreciação de ações coletivas e garantia dos direitos ambientais.

${ }^{24}$ MILARÉ, Édis. Direito do ambiente. A gestão ambiental em foco. 5. ed. São Paulo, 2009. 


\section{PESQUISAS SOCIOJURÍDICAS}

O juiz tem também o papel de educador ambiental, na medida em que está em posição de ser ouvido. Segundo Watanabe: “[...] é o recrutamento mais aprimorado de juízes e seu permanente aperfeiçoamento cultural, face à crescente complexidade das relações sociais, transformações sociais rápidas e profundas, criação assistemática de leis [...]”. O Poder Judiciário deve fazer do ambiente equilibrado sua luta particular.

A melhor maneira de justificar o papel do magistrado na efetivação da justiça ambiental, tese aqui defendida, é através do CLS e da herança teórica que proporciona. De acordo com essa corrente, a decisão judicial serve a um interesse pessoal, à ideologia do julgador. Assim, como foi demonstrado, a justiça ambiental depende especialmente do Ministério Público e do próprio magistrado. No entanto, tomando o CLS como paradigma, essa justiça do meio ambiente estaria seriamente prejudicada se não servir à ideologia do magistrado em questão. Dessa forma, para provar a hipótese que muitas decisões judiciais que se esquivam de garantir justiça ambiental o fazem a serviço de uma ideologia pessoal ou de classe, vai-se tomar a seguir o exemplo do Condomínio Alamoana.

\section{O CLS COMO FORMA DE ABORDAR A GARANTIA DA JUSTIÇA AMBIENTAL: $O$ CASO DO CONDOMÍNIO ALAMOANA}

Como restou demonstrado, os crits defendem uma postura mais radical na abordagem do direito, admitindo que a decisão judicial é materialização através de instrumentos jurídicos de uma ideologia pessoal do julgador. Quando se aborda a questão da garantia da justiça ambiental sob esse viés, é possível trazer alguns questionamentos sobre a segurança da legislação ambiental. $\mathrm{O}$ fato é que, por melhor assegurado em lei que determinada norma de caráter ambiental seja, a segurança ambiental ainda estará à mercê da ideologia dos julgadores.

$\mathrm{O}$ caso do Condomínio Alamoana, em João Pessoa, pode ser paradigmático dessas dificuldades da garantia de direitos apontadas pelo CLS. O referido empreendimento é um condomínio horizontal localizado na área de preservação permanente (APP) do rio Paraíba, que compreende uma faixa de terra de 500 metros a partir da margem do rio, na Floresta Nacional da Restinga, a chamada Mata do Amém.

Os relatórios administrativos do Ibama indicam que a área do condomínio que estava na faixa de 500 metros que configura a APP foi desmatada pela empresa responsável pelo empreendimento. Mais que isso, a área desmatada serviu para a construção de piscina, quadras de esportes e pavilhão de entretenimento do condomínio, impedindo completamente a regeneração da vegetação desmatada.

Diante do relatório do Ibama que descrevia a situação de desrespeito à proteção ambiental e do decorrente embargos às obras pelo órgão, $o$ Ministério Público instaurou um procedimento administrativo em 2006. Desse procedimento foi afirmado um termo de ajustamento de conduta (TAC) do qual fizeram parte o MPF, o Ibama, a Sudema, a Superintendência do Patrimônio da União (SPU-PB) e a IPI Urbanismo, Construções e Incorporações Ltda., a empresa responsável pelas obras do condomínio.

$\mathrm{O}$ referido TAC visava amenizar a questão da invasão do condomínio na área da Floresta Nacional de Cabedelo. No acordo, a empresa tomou responsabilidade sobre uma série de medidas que tentava trazer compensação aos danos causados, eminentemente projetos que se reverteriam para a infraestrutura da Floresta danificada, como inventário da fauna, um projeto arquitetônico etc. Além do TAC, a empresa assinou ainda outro acordo com a SPU-PB, que delimitava a área de construção excluindo a APP, de modo a não causar mais danos.

No entanto, ambos os acordos foram desrespeitados pelos empresários, o que acarretou o ajuizamento, em 2010, da Ação Civil Pública n. 0004384-19.2010.4.05.8200, pedindo a condenação dos réus em $\mathrm{R} \$ 2$ milhões por dano ambiental. A 1 ${ }^{\text {a }}$ Vara da Justiça Federal concedeu liminar, impedindo qualquer obra dentro do condomínio. Interessante perceber, aqui, dois trechos da referida decisão: 
[...] permitir o livre prosseguimento das obras do condomínio, antes de uma solução final, não se afigura vantajoso para o empreendedor, porque as relações comerciais tendem a se aprofundar, sendo muito mais difícil retrocedê-las, em caso de resultado final desfavorável, além do que a própria recuperação do meio-ambiente pode se tornar muito mais onerosa.

\section{E, mais adiante:}

[...] a jurisprudência do Superior Tribunal de Justiça tem fortemente se inclinado pela primazia da proteção ambiental, mesmo em face de obras de grande porte e que já tenham sido até concluídas.

O primeiro trecho citado é indicativo da teoria da hierarquização do CLS, na medida em que é possível perceber a preocupação do magistrado com as consequências das construções, não para o meio ambiente, mas para o empresário. O que o movimento dos crits ensina é que os juízes são elevados na hierarquia social, de modo que encontram mais coincidências ideológicas com empresários e outras camadas socais em patamar hierárquico superior do homem comum. Assim, a percepção de que o juiz, nesse caso, preocupa-se com eventuais prejuízos sofridos pelos empresários na eventualidade de uma condenação das obras pode ser explicada pelo CLS: a ideologia do magistrado aparece aqui como uma ideologia similar e compatível com os interesses do empresário-réu.

Da mesma forma, o segundo trecho citado tem relevância para a proposta aqui trazida, conquanto, em 2012, funcionários da Floresta de Cabedelo constataram que o condomínio retirou ilegalmente, mais uma vez, a vegetação de floresta no entorno do empreendimento. Foram, então, lavrados mais dois autos de infração relativos às áreas de vegetação retirada e estipuladas novas multas no valor de R \$ 107 mil.

Porém, contrariando toda a legislação posta no ordenamento no sentido de garantir justiça ambiental, o condomínio continua permitido pelo Judiciário. A própria liminar que suspende o direito de construir no local garante que o entendimento do Judiciário, através do STJ, em casos dessa natureza é o de garantir proteção ambiental e ordenar a demolição das obras irregulares, como colocado no segundo trecho da jurisprudência do condomínio Alamoana.

Assim, o que se tem aqui é uma construção em absoluta incompatibilidade com a garantia de proteção do meio ambiente que, contrariando a lógica do direito, continua permitida. Não veio ainda nenhuma decisão definitiva do Poder Judiciário no sentido de garantir justiça e ordenar o fim do empreendimento.

Tomando, então, os ensinamentos do CLS, é possível concluir que a falta de interesse do Judiciário em garantir a justiça ambiental nesse caso concreto pode ser interpretada como a exteriorização da ideologia de que o empreendimento comercial se sobrepõe à proteção do meio ambiente, que também é compatível com a ideia de que a ideologia de classe dos magistrados tem profunda identidade com a dos empresários.

Dando um passo mais para trás, é possível também questionar como um empreendimento com essa nocividade à área de preservação pôde ser autorizado em primeiro lugar? A obra foi aprovada pela prefeitura e, mesmo que não se trate de juízes propriamente nesse caso, houve um julgamento de valor em âmbito administrativo da Prefeitura que autorizou a iniciação das construções. Esses julgadores administrativos também usam de seu poder de decisão para afirmar suas ideologias pessoais. Assim, a própria autorização para a construção do condomínio é uma afirmação do CLS.

Resta ainda dizer que, mesmo com a vigência da liminar que proíbe novas construções no local, a empresa continua com as vendas dos lotes residenciais como se não houvesse nenhum impedimento para sua colocação naquele local.

Mas o que causa mais desconforto é a passividade do judiciário que não fala em demolição da construção, como se verifica em outras decisões de mesma natureza. Já foram constatados diversos atos de degradação de áreas de preservação permanente em oportunidades diferentes, como demonstrado nos autos de infração do Ibama. A garantia de justiça ambiental se efetiva com a demolição das construções, como corroborado na legislação nacional, de modo que a área possa recuperar-se dos danos 
e se desenvolver novamente. No entanto, ao que parece, a ideologia pessoal dos julgadores em questão sugere entrar em conflito com a justiça ambiental, impedindo sua concretização.

A decisão judicial pode ser uma arma na garantia da justiça ambiental, na medida em que, tomando os ensinamentos do CLS, a decisão judicial é uma decisão pessoal fundamentada em direito. Desse modo, um Judiciário proativo e crente nas premissas ambientais pode ser mais eficiente que qualquer legislação protetiva. $\mathrm{O}$ que se vê nesse caso em concreto é a confirmação dessa ideia. A passividade dos magistrados garante a concretização de uma injustiça ambiental, quando se permite, por anos a fio, uma construção com nocividade dessa natureza.

Desse modo, a garantia da justiça ambiental nos moldes do CLS depende de um magistrado que tenha para si a proteção ambiental como algo necessário. É a ideologia pessoal do juiz que acredita que deve haver garantia do meio ambiente que efetiva a justiça ambiental. Da mesma forma, se o magistrado não possui ideologia nesse sentido, a justiça ambiental está fadada ao insucesso no caso concreto.

O juiz tem o poder de concretizar a feitura de justiça no caso concreto. Tomando o CLS como paradigma, a decisão judicial é uma decisão de caráter pessoal que usa a legislação para lhe dar respaldo. Assim, a efetivação da justiça ambiental depende dos contornos que o magistrado dá para o caso concreto. Usando de sua própria consciência ao permitir que sua ideologia aflore na sentença, o magistrado tem o condão de garantir justiça ambiental. Da mesma forma, se sua ideologia pessoal não é condizente com a proteção do meio ambiente no caso concreto, essa garantia está seriamente prejudicada.

\section{CONCLUSÃO}

Nesses termos, considerando os mecanismos dispostos na legislação para se garantir justiça ambiental e fazendo a dicotomia com o CLS, que ensina que a decisão judicial é uma decisão fundamentada na ideologia pessoal do julgador, têm-se as dificuldades de concretização da proteção ambiental.
No caso analisado como paradigma, constatase que uma atuação frouxa do Judiciário, mesmo diante de provas irrefutáveis que corroboram uma condenação e uma possível ordem de demolição do empreendimento construído em área de preservação, é suficiente para garantir injustiça ambiental. É possível, então, concluir que a ideologia desse julgador, como ideologia de classe, é compatível com a dos empresários responsáveis pelo empreendimento deturpador das regras ambientais. E, ademais, a ideologia desse magistrado, revelada através da placidez de sua atuação, é contrária à garantia da justiça ambiental, ao menos nesse caso específico.

Nesse sentido, é inevitável concluir que a hipótese inicial de que os ensinamentos do CLS acerca de encontrar a ideologia que condiciona a decisão judicial vão explicar as decisões judiciais que se esquivam de garantir justiça ambiental está confirmada. A concretização da justiça ambiental depende de um fator particular: da vontade do magistrado. Assim, se a ideologia desse julgador não o leva a agir no sentido de garantir justiça, ela não acontecerá, pois sua ideologia o condiciona a se comportar contrariamente.

\section{REFERÊNCIAS}

ARNAUD, André-Jean et al. (Org.). Dicionário enciclopédico de teoria e sociologia do direito. Trad. Patrice Charles e F. X. Willaume. Rio de Janeiro: Renovar, 1999.

CARDOZO, Benjamin. The nature of judicial process. New York: Dover, 2005.

CASTILHO, Adriana Guedes de. Entre a justiça e a injustiça ambiental: atuação do poder judiciário nos conflitos ambientais. 2012, 114f. Dissertação (Mestrado)-Programa de Pós-Graduação em Ciências Jurídicas da Universidade Federal da Paraiba. João Pessoa, 2012.

FREITAS, Lorena de Melo. O realismo jurídico como pragmatismo: a retórica da tese realista de que direito é o que os juízes dizem que é direito. 
Recife: o autor, 2009.

GODOY, Arnaldo. O critical legal studies movement de Roberto Mangabeira Unger. Revista Jurídica. Brasília, v. 8, n. 82, p. 49-63, dez./jan. 2007.

O movimento Critical Legal Studies e Duncan Kennedy: notas sobre a rebeldia acadêmica no direito norte-americano. Disponível em: <http://www.arnaldogodoy.adv. br/artigos/kennedy.htm>. Acesso em: 16 ago. 2013.

PACHECO, Tânia [Blog]. Combate racismo ambiental. Globo ecologia: entenda a importância do trabalho da rede brasileira de justiça ambiental. 10.07.2012. Disponível em: <http:// racismoambiental.net.br/tag/rede-brasileira-dejustica-ambiental/>. Acesso em: 16 ago. 2013.

JAMES, William. Pragmatism's conceptions of truth. New York: Dover Publications, 1986.

KENNEDY, Duncan. A critique to adjdudication. Cambridge: Harvard University Press, 1997.

La critica de los derechos em los Critical Legal Sudies. Disponível em: <http://www. palermo.edu/derecho/publicaciones/pdfs/ revista_juridica/n7N1-Julio2006/071Juridica02. pdf >. Acesso em: 19 ago. 2013.

MEDEIROS, Gilmara Joane Macedo. Realismo Jurídico e Critical Legal Studies: diferentes posturas críticas do direito. Anais... II Encontro PROCAD UFAL-UFPE-UFPB. Recife, 2011.

MILARÉ, Édis. Direito do ambiente. A gestão ambiental em foco. 5. ed. São Paulo, 2009.

UNGER, Roberto M. The Critical Legal Studies movement. Cambridge: Harvard University Press, 1983. 